\title{
Molecular electrostatic potential of the reaction center as a descriptor of the reactivity of arylsulfonyl halides
}

\author{
C Evgeny N. Krylov, ${ }^{1 *}$ and Lyudmila V. Virzum ${ }^{2+}$ \\ ${ }^{1}$ Department of Fundamental and Applied Chemistry. Ivanovo State University. \\ Ermak St., 39. Ivanovo, 153025. Russia. Phone: +7 (4932) 37-37-03. E-mail: enk2000S @yandex.ru \\ ${ }^{2}$ Ivanovo State Agricultural Academy Named D.K. Belyaev. Sovetskaya St., 45. Ivanovo, 153012. Russia. \\ Phone: +7 (4932) 32-81-44.E-mail: virzum@list.ru
} \begin{abstract}
Keywords: sulfonyl halides, hydrolysis, isotopic exchange, molecular electrostatic potential.
\end{abstract}
*Supervising author; ${ }^{+}$Corresponding author

\begin{abstract}
To study the reactivity of arylsulfonyl halides, the molecular electrostatic potential (MEP) was considered for the first time as a descriptor. The reaction of hydrolysis of aromatic sulfonyl halides in the medium of mixed acetone-water solvents (according to the literature data of rate constants) was used as a model. The calculation of the structural parameters of the molecules of substituted arylsulfonyl halides was carried out using the ADF2014 software package at the level of the DFT/M06/6-311+G* (PCM) theory. It was found that the magnitude of the MEP on the sulfonyl sulfur atom is very sensitive to changes in the structure of substrates, which makes it possible to determine the change in the ratio between the rate of nucleophilic attack and anionoid abstraction of the leaving group. In particular, using the example of the hydrolysis reaction of substituted thiophenesulfonyl chlorides, it was shown that the acceleration of the reaction is observed with an increase in the donor properties of the substituents and the associated increase in the negative MEP value on the sulfonyl sulfur atom. The antibate character of the dependence of the hydrolysis constant values on the IEP value indicates that not the nucleophilic attack is the rate determining in the interaction of thiophene sulfonyl chlorides and the hydroxyl anion in this sample, but the abstraction of the chloride anion. This reaction has an unstable mechanism, when the ratio between the degree of S-nucleophile bond formation and S-halogen bond cleavage changes. This makes it possible to use MEP as a descriptor of reactivity in the hydrolysis of aryl sulfonyl halides and to elucidate the details of changes in the structure of transition states during the implementation of mechanisms other than pure SN2 mechanism.
\end{abstract}

\section{References}

[1] Concepts and methods in modern theoretical chemistry. Electronic structure and reactivity. Ghosh S.K., Chattaraj P.K. Eds. N.-Y.: CRC Press. 2013. 450p.

[2] R.G. Parr, W. Yang. Density Functional Theory of Atoms and Molecules. N.-Y.: Oxford University Press. 1989. 352p.

[3] R.G. Pearson. Chemical hardness: applications from molecules to solids. Weinheim: Wiley-VCH. 1997. 198 p.

[4] P. Hohenberg, W. Kohn. Inhomogenous electron gas. Phys. Rev. 1964.Vol.136. No.3. P.B8640B871.

[5] P. Geerlings, F. De Proft, W. Langenaeker. Conceptual Density Functional Theory. Chem. Rev. 2003. Vol.103. No.5. P.1793-1873.

[6] N. Sukumar Ed. A matter of density. Expolring th electron density concept in the chemistry, biological and materials sciences. Hoboken: J.Wiley \& Sons, Inc. 2013. 318p.

[7] E.N. Krylov, L.V. Virzum, T.A. Shapovalova, and M.S. Gruzdev. Atomic electrostatic potential on the reaction center and on the leaving group as a descriptor of processes of an aminolysis phenyl- and tiophenylacetates and hydrolysis of acetanilides. Butlerov Communications. 2018. Vol.55. No.9. P.128137. DOI: $10.37952 /$ ROI-jbc-01/18-55-9-128

[8] Toro-Labbe A., Ed Theoretical aspects of chemical reactivity. Amsterdam: Elsevier. 2007. 321 p.

[9] J.S. Murray, K. Sen, Eds. Molecular electrostatic potentials. Concepts and applications. Amsterdam: Elsevier. 1996. 664p. 
[10] R. Bonaccorsi, E. Scroccco, J. Tomasi. Molecular SCF Calculations for the Ground State of Some Three-Membered Ring Molecules: $\left(\mathrm{CH}_{2}\right)_{3},\left(\mathrm{CH}_{2}\right)_{2} \mathrm{NH},\left(\mathrm{CH}_{2}\right)_{2} \mathrm{NH}_{2}{ }^{+},\left(\mathrm{CH}_{2}\right)_{2} \mathrm{O},\left(\mathrm{CH}_{2}\right)_{2} \mathrm{~S},(\mathrm{CH})_{2} \mathrm{CH}_{2}$ and $\mathrm{N}_{2} \mathrm{CH}_{2}$. J. Chem. Phys. 1970. Vol.52. P.5270-5284.

[11] P. Politzer, J.S. Murray. Molecular electrostatic potentials. Some observations. N.-Y.: CRC Press. 2013. 450p. P.181-199.

[12] P. Politzer, J.S. Murraj. Fundamental nature and role of the electrostatic potentialin in atoms and molecules. Theor. Chem. Acc. 2002. Vol.108. No.3. P.134-142.

[13] R.F. Stewart. On the mapping of electrostatic properties from Bragg diffraction data. Chem. Phys. Lett. 1979. Vol.65. P.335-342.

[14] K.B. Wiberg, P.R. Rablen. Comparison of atomic charges derived via different procedures. J. Comput. Chem. 1993. Vol.14. P.1504-1518.

[15] D. Cheshmedzhieva, S. Ilieva, B. Hadjieva, T. Trayanova, B. Galabov. Reactivity of acetanilides in the alkaline hydrolysis reaction: theory and experiment. Mol. Phys. 2009. Vol.107. No.8-12. P.1187-1192.

[16] E.N. Krylov., L.V. Virzum. Acidity of arylsulfonilamides as function of quantum chemical parameters of sulfanilamide nitrogen. Russian Chemical Bulletin. 2019. Vol.68. No.3. P.527-531.

[17] M.S. Gruzdev, L.V. Virzum, E.N. Krylov. Reaction of aromatic hydrodechlorination: guantumchemical diagnostics of the mechanism. Butlerov Communications. 2015. Vol.41. No.2. P.115-120. DOI: $10.37952 /$ ROI-jbc-01/15-41-2-115

[18] E.N. Krylov, M.S. Gruzdev, L.V. Virzum. Acidity of aromatic sulfoacids in gas and water phase. Butlerov Communications. 2015. Vol.42. No.6. P.117-123. DOI: 10.37952/ROI-jbc-01/15-42-6-117

[19] A. Arcoria, F.P. Ballistrelli, E. Spina, G.A. Tomaselli. Nucleophilic substitution sulphonyl sulphur. Part 4. Hydrolysis of substituted thiophensulphonyl halides in water - acetone mixture. J. Chem. Soc. Perkin Trans. II. 1988. P.1793-1798.

[20] E. Ciuffarin, L. Senatore. A Hammett study of alkaline hydrolysis of benzenesulphonyl fluoride. Tetrahedron Letters. 1974. No.17. P.1635-1636.

[21] S.N. Ivanov. Effects of the medium in solvolysis reactions of functional derivatives of aromatic sulfonic acids. Dissertation of Doctor of Chemical Sciences. Ivanovo. 2004. 328c. (russian)

[22] I. Lee, I.S. Koo, H.K. Kang. $\mathrm{S}_{\mathrm{N}} 2$ Transition State Variation in the Benzenesulfonyl Chloride Solvolysis. Bulletin of Korean Chemical Society. 1981. Vol.2. No.2. P.41-45.

[23] V.I. Dvorkin. Metrology and quality assurance of quantitative chemical analysis. Moscow: Chemistry. 2001. 263p. (russian)

[24] E.G. Gordeev. Effect of the electronic structure of the dicarba-closo-dodecarborans (12) on their reactivity. Aut ... the diss. of the candidate of chemical sciences. Moscow: Moscow State Academy of fine chemical technology. 2007. 26p. (russian)

[25] O. Rogne. Kinetic of the neutral and alkaline hydrolysis of aromatic sulphonyl chlorides in water. $J$. Chem. Soc. (B). 1968. P.1294-1296.

[26] A.S. Dneprovskiy, T.S. Temnikova. Theoretical foundations of organic chemistry. Leningrad: Chemistry. 1991. 560p. (russian)

[27] R.G. Pearson. Hard and Soft Acids and Bases. The Evolution of a Chemical Concept. Coord. Chem. Rev. 1990. Vol.100. P.403-425.

[28] R.J. Cremlyn, P.H. Gore, A.O. Ikejiani, D.F.C. Morris. Kinetics of chlorine-isotopic exchange between litium chloride and substituted benzene sulphonyl chloride in sulpholan solution. J. Chem. Res. (S). 1982. P.194-195.

[29] E.J. Baerends, T. Ziegler, J. Autschbach, D. Bashford, A. Bérces, F.M. Bickelhaupt, C. Bo, P.M. Boerrigter, L. Cavallo, D.P. Chong, L. Deng, R.M. Dickson, D.E. Ellis, M. van Faassen, L. Fan, T.H. Fischer, C. Fonseca Guerra, M. Franchini, A. Ghysels, A. Giammona, S.J.A. van Gisbergen, A.W. Götz, J.A. Groeneveld, O.V. Gritsenko, M. Grüning, S. Gusarov, F.E. Harris, P. van den Hoek, C.R. Jacob, H. Jacobsen, L. Jensen, J.W. Kaminski, G. van Kessel, F. Kootstra, A. Kovalenko, M.V. Krykunov, E. van Lenthe, D.A. McCormack, A. Michalak, M. Mitoraj, S.M. Morton, J. Neugebauer, V.P. Nicu, L. Noodleman, V.P. Osinga, S. Patchkovskii, M. Pavanello, P.H.T. Philipsen, D. Post, C.C. Pye, W. Ravenek, J.I. Rodríguez, P. Ros, P.R.T. Schip-per, H. van Schoot, G. Schreckenbach, J.S. Seldenthuis, M. Seth, J.G. Snijders, M. Solà, M. Swart, D. Swerhone, G.t e Velde, P. Vernooijs, L. Versluis, L. Visscher, O. Visser, F. Wang, T.A. Wesolowski, E.M. van Wezenbeek, G. Wiesenekker, S.K. Wolff, T.K. Woo, A.L. Yakovlev. ADF2014. SCM. Theor etical Chemistry. Vrije Universiteit. Amsterdam. The Netherlands. 2014. http://www.scm.com.

[30] J. Tomasi, B. Mennucci, R. Cammi. Quantum mechanical continuum solvation models. Chem. Rev. 2005. Vol.105. No.8. P.2999-3093. 
MOLECULAR ELECTROSTATIC POTENTIAL OF THE REACTION CENTER AS A DESCRIPTOR...

[31] A.R. Campanelli, A. Domenicano, F. Ramondo, I. Hargittai. Group Electronegativities from Benzene Ring Deformations: A Quantum Chemical Study. J. Phys. Chem. A 2004. Vol.108. No.22. P.4940-4948.

[32] F.P. Ballistrelli, A. Cantone, E. Maccarone, G.A. Tomaselli, M. Tripolone. Nucleophilic substitution at sulphonyl sulphur. Part 2. Hydrolysis and alcoholysis of aromatic sulphonyl chlorides. J. Chem. Soc., Perkin Trans. 2, 1981. No.3. P.438-441. 